\title{
PENGUATAN KONSEP AJARAN TRI HITA KARANA MELALUI SEKE BHATRE DI BANJAR LUMBUNG SARI, DESA PAKRAMAN DENPASAR
}

\author{
I Gusti Ketut Widana ${ }^{1}$ and I Gde Widya Suksma ${ }^{2}$
}

\begin{abstract}
ABSTRAK
Sebagai agama wahyu yang maha sempurna, ajaran Hindu sangat kaya dengan konsep ajaran ideal. Namun, apa yang menurut konsep ajaran itu begitu ideal dan baik serta berguna bagi kemuliaan hidup manusia, seringkali diabaikan. Oleh karena itu, diperlukan terobosan baru untuk mengejawantahkan ajaran ideal Hindu secara konseptual dalam tataran kontekstual. Seperti konsep ajaran Tri Hita Karana yang penguatannya dapat diimplementasikan melalui kegiatan "Seke Bhatre", dengan cara melakukan Tirthayatra yang dalam pelaksanaannya mensinergikan ajaran bhakti (kehadapan Tuhan), tresna (kepada sesama manusia) dan eling (terhadap alam lingkungan).
\end{abstract}

\section{Kata kunci : penguatan, tri hita karana, seke bhatre}

\section{Pendahuluan}

Ajaran Hindu dari segi konsep memang tak dapat disangsikan lagi kebenarannya. Umatpun dengan mantap meyakini kebenarannya dalam kesempurnaan. Namun tak dapat dimungkiri, bagi umat awam, konsepsi-konsepsi ajaran Hindu terkesan sulit dipahami. Apalagi dalam praktiknya terutama dalam urusan ritual dengan berbagai bentuk, jenis dan makna upakara bebantennya seringkali dirasakan rumit. Kecuali bagi sebagian kecil umat yang memang secara khusus membidangi atau menekuni urusan praktik ritual. Diluar kelompok itu, kebanyakan umat hanya menerima dan kemudian menjalankannya secara gugon tuwon (percaya begitu saja) dengan prinsip anak mulo keto (karena memang sudah begitu adanya).

Memang, agama Hindu tidak secara ketat mengharuskan umatnya untuk hafal berbagai macam konsepsi ajaran, apakah itu teologi, filosofi, atau teorinya. Karena bagi Hindu yang dipentingkan adalah pengamalannya (karma) bukan sekedar pengetahuan (jnana) yang masih berupa teori yang bisa dihafalkan. Menurut Hindu, teori yang baik adalah praktiknya, bukan

\footnotetext{
${ }^{1}$ Fakultas Pendidikan Agama dan Seni, E-mail igustiketutwidana1805@gmail.com

${ }^{2}$ Fakakultas. Pendidikan Agama dan Seni, E-mail : widyasuksma@yahoo.com
} 
pengetahuan hafalannya. Namun, tentu akan lebih baik dan sempurna lagi,jika bagian pengetahuan (tattwa-jnana) yang telah diketahui, dimengerti, dan dipahami, dilanjutkan dengan pengamalannya. Sehingga antara teori dan praktik menjadi satu kesatuan gerak dalam kehidupan umat Hindu sehari-hari.

Mensinergikan teori dan praktik itu, salah satu cara sederhana tetapi bermakna sekaligus berguna yang dapat dilakukan adalah dengan menerapkan konsep ajaran Tri Hita Karana (tiga hal yang menyebabkan hidup sejahtera dan bahagia) melalui kegiatan Tirthayatra yang dilakukan kelompok masyarakat Hindu yang menamakan dirinya "Seke Bhatre" dan beralamat di Br. Lumbung Sari, Desa Pakraman Denpasar. Nama kelompok ini diambil dari kata "Sekeaa" yang menurut Kamus Bahasa Bali-Indonesia (Antara, 2009: 635) berarti kelompok/perkumpulan, sedangkan istilah "Bhatre" sebenarnya merupakan akronim dari kata "Bhakti-Tresna-Eling".

Secara teoritis konsep "Bhatre" merupakan implementasi ajaran Tri Hita Karana yang dalam praktiknya dikemas dalam suatu kegiatan Tirthayatra (perjalanan suci) ke Pura dengan cara memadukan ajaran tentang "Bhakti" kehadapan Tuhan, disertai dengan pengamalan ajaran "Tresna" yaitu cinta kasih kepada sesama manusia, serta ditambah dengan pembuktian rasa "Eling" dengan cara melakukan kegiatan yang berhubungan dengan cinta lingkungan, seperti membersihkan area Pura dari sampah, sampai melakukan penanaman pohon, terutama yang diperlukan dalam upakara yadnya.

Melalui konsep "Bhatre" ini umat dengan mudah, murah dan sederhana dapat menguatkan bahkan meningkatkan kualitas Sraddha (iman) dan Bhakti (taqwa) sebagai hamba Tuhan dalam kehidupan sehari-hari. Ibarat battery sebagai sumber energi yang setiap saat bisa kehilangan kekuatannya (soak), sehingga harus dicas (charger) ulang agar terisi daya listriknya sehingga tetap bisa digunakan untuk menyambung atau menangkap sinyal/gelombang/frekuensi dalam berkomunikasi. Begitupun dengan konsep "Bhatre", setiap saat seorang umat bisa juga kehilangan kekuatan daya/energi rohaninya, sehingga wajib dengan rutin dicas agar tetap dapat "menyambung hubungan" dengan Tuhan, sesama manusia dan juga lingkungan alam.

Analoginya, jika mengisi kekuatan daya battery dilakukan pada stop kontak listrik, maka cara menambah kekuatan energi "Bhatre" adalah dengan disiplin berbhakti kehadapan Tuhan, lalu rajin membantu atau menolong sesama manusia dan juga dengan rutin memelihara, merawat serta melestarikan keberadaan alam lingkungan, dimana tumbuh 
berkembang segenap makhluk hidup (tumbuhan dan khewan) yang sangat berjasa bagi kelangsungan kehidupan manusia.

Apa yang selama ini dilakukan umat Hindu dengan lebih memusatkan perhatian, terutama pengalokasian dana/materi hanya sebesar-besarnya untuk kepentingan upacara ritual-yadnya (rituality) memang tidak salah, namun akan lebih baik dan bermakna lagi jika disinergikan dengan cara yang bermanfaat langsung bagi upaya pembangkitan kesadaran sosial (humanity) dan kepedulian terhadap alam lingkungan (ekology).

Berangkat dari latar belakang itulah, Seke Bhatre yang telah berdiri sejak tahun 1996 dibawah naungan Yayasan Swadharma Indonesia ini, namun karena kian melemahnya semangat para pengurus dan anggotanya, membuat aktivitas Tirtayatra yang sebelumnya rutin dijalankan akhirnya vakum untuk beberapa waktu lamanya. Mempertimbangkan manfaat yang didapat dari Seke Bhatre ini, melalui pendekatan sekaligus pendampingan intensif, akhirnya Seke Bhatre yang diketuai I Nyomnan Lastra (51 tahun) dan beranggotakan sekitar 40 orang ini bergeliat kembali menghidupkan sekaligus menguatkan kegiatan Tirthayatra berbasis konsep "Bhatre" (Bhakti-Tresna-Eling).

\section{Metode Pelaksanaan}

Berpijak pada paparan diatas, maka dilakukanlah kegiatan pengabdian kepada masyarakat dengan sasaran kelompok Seke Bhatre ini. Adapun metode yang digunakan sebagai usaha penguatan aktivitas Seke Bhatre adalah dengan cara sosialisasi, partisipasi (pendampingan), monitoring dan evaluasi.

Kegiatan tahap pertama yang dilakukan adalah melalui sosialisasi tentang apa, mengapa dan bagaimana meningkatkan sekaligus menguatkan kualitas Sraddha Bhakti melalui kegiatan Tirthayatra berbasis "Bhatre". Pada tahap sosialisasi ini lebih banyak diberikan pemahaman tentang pengetahuan atau konsep ajaran Hindu, terutama yang mengajarkan tentang landasan terbentuknya Seke "Bhatre" yang bersumber dari ajaran Tri

\section{Hita Karana.}

Tahapan selanjutnya merupakan kegiatan tahap kedua, yaitu ikut serta berpartipasi melakukan pendampingan agar terus terjadi penguatan sraddha dan bhakti. Pendampingan dilakukan untuk turut merasakan sekaligus melihat celah sekiranya dapat dicegah jika seandainya terjadi penurunan semangat Seke Bhatre melakukan kegiatan Tirthayatra. 
Kegiatan tahap ketiga, adalah monitoring dan evaluasi. Monitoring dan evaluasi dengan indikator-indikator yang dapat diamati sebagai bentuk kemajuan setelah melakukan kegiatan pendampingan. Bahwa kelompok Seke Bhatre dapat dengan intensif dan konsisten melakukan kegiatan Tirthayatra berbasis Bhakti-Tresna-Eling. Sehingga terjadi penguatan atau peningkatan sradha bhakti umat, dalam hal ini anggota Seke Bhatre, beserta anggota keluarganya yang kerap mengikuti kegiatan ini.

\section{Hasil Dan Pembahasan}

\subsection{Orientasi dan Sosialisasi}

Sosialisasi pertama dipaparkan tentang pengetahuan yang berkaitan dengan konsep "Bhatre". Bahwa sebenarnya istilah "Bhatre" itu merupakan akronim dari kata "BhaktiTresna-Eling" yang landasan filosofinya bersumber dari ajaran Tri Hita Karana, yaitu tiga hal yang menyebabkan hidup sejahtera dan bahagia (Wirawan, 2018:2). Implementasinya dilakukan dengan :

(a) Terus menjalin hubungan religis (bhakti) antara umat dengan Ida Sanghyang Widhi Wasa (Tuhan Yang Maha Kuasa),

(b) Tetap membangun hubungan sinergis (tresna) antara sesama umat manusia,

(c) Tidak lupa menjaga hubungan harmonis (eling) antara manusia dengan alam lingkungan beserta segala isinya.

Ketiga hubungan ini dapat dilaksanakan melalui suatu kegiatan yang lazim disebut Tirthayatra, atau Dharmayatra.

Sosialisasi kedua berkenaan dengan pemahaman tentang arti Tirthayatra. Bahwa secara sederhana Tirthayatra berarti kegiatan mengunjungi tempat-tempat suci/kahyangan, dalam hal ini Pura (Titib, 1983: 41). Lebih luas lagi Tirthayatra juga mengandung makna sebagai kegiatan keagamaan yang dilandasi niat bhakti yang tulus ikhlas untuk meningkatkan dan atau menguatkan kehidupan rohani (spiritual) umat dengan cara datang (pedek tangkil) ke Pura/Kahyangan/Candi sebagai tempat suci Hindu dimana Ida Sanghyang Widhi Wasa (Tuhan Yang Maha Kuasa) dan manifestasi-Nya bersthana.

Sosialisasi ketiga lebih menekankan pada bagaimana agar aktivitas Tirthayatra berbasis "Bhakti-Tresna-Eling" dapat diimplementasikan dalam rangka penguatan atau peningkatan sradha bhakti anggota seke, yaitu dengan cara : 1) Ketika tiba di tempat suci/Pura itu anggota seke mula-mula menjalankan kewajiban beragama dengan menghaturkan persembahan upakara bebanten (sesaji); 2) dilanjutkan dengan 
persembahyangan (mengucapkan mantram Tri Sandhya dan melakukan Panca Sembah). Setelah selesai persembahyangan, dilanjutkan mohon (nunas) air suci (tirtha) dan bija; 3) Menanamkan keyakinan bahwa menurut keyakinan Hindu, melakukan Tirthayatra ini sangat utama pahalanya, yang bisa dilakukan oleh semua lapisan umat, termasuk orang-orang miskin. Hal ini dengan jelas disuratkan di dalam kitab suci Sarasamuscaya, sloka 279 :

"Apan mangke kottamaning tirthayatra, atyanta pawitra, lwih sangkeng kapawananing yajna, wenang ulahakena ring daridra”.

Artinya :

Sebab keutmaan tirthayatra itu, amat suci, lebih utama dari pada penyucian dengan yajna, dan dapat dilakukan oleh siapapun termasuk orang miskin (Pudja, 1981: 151).

Kegiatan Tirthayatra ini dapat dikatakan tergolong murah (dari segi biaya), bersifat alamiah dan banyak hikmah sekaligus mendapatkan berkah. Selain dapat menghaturkan sembah bhakti kehadapan Ida Sanghyang Widhi beserta manifestasi-Nya, oleh karena dilakukan dengan mengunjungi tempat suci (kahyangan/Pura/Candi) diluar lingkungan tempat tinggal, bahkan hingga keluar daerah, berarti ada juga kesempatan bagi anggota seke dan keluarganya untuk menyegarkan diri (refreshing) dalam arti rekreasi ke berbagai tempat/daerah. Sehingga dengan demikian, melalui satu kesempatan Tirthayatra sekaligus dapat menjaga kebugaran atau kesehatan badan dan kesegaran pikiran. Sebab tidak jarang tempat-tempat suci yang dituju letaknya belum terjangkau akses jalan, malah banyak yang lokasinya jauh dari pemukiman, seperti ada di dalam goa, tengah hutan, hingga di lereng/puncak bukit/gunung. Sehingga untuk mencapainya harus ditempuh dengan berjalan kaki, sembari melihat dan menikmati panorama pemandangan alam yang begitu indahnya. Pendek kata, melalui Tirthayatra, manfaat jasmani dan rohani sekaligus diperoleh dan dirasakan, sehingga kondisi umat tetap sehat baik secara fisikal maupun spiritual : Pikiran (mind) disucikan, jiwa (soul) disehatkan, dan badan (body) disegarkan.

\subsection{Pendampingan}

Setelah sosialisasi dilaksanakan secara intensif, dilanjutkan dengan melakukan pendampingan langsung pada setiap kegiatan Tirthayatra berbasis bhakti-tresna-eling. Tujuannya agar pengetahuan yang telah diberikan dan ditanamkan dapat diimplementasikan sesuai ranahnya, yaitu :

1) Dalam ranah "Bhakti", realisasi implementasinya dapat diwujudkan dengan : 
(a) Menjalankan kewajiban utama sembah bhakti kehadapan Ida Sanghyang Widhi dan Ida Bhatara-Bhatari atas dasar kesadaran bahwa hanya kepada Beliau Sang Maha Pencipta dan pemberi perlindungan, umat Hindu wajib menghaturkan sembah bhakti (nyakup tangan nylepit bunga), sebagai cetusan rasa bersyukur dan terimakasih (angayu bagia dan parama suksma) atas segala berkah anugrah melimpah yang telah diterima dan dinikmati umat.

(b). Memenuhi kewajiban sebagai umat terkait kepentingan untuk membangun, merawat, dan menjaga serta melaksanakan kewajiban mayajna di tempattempat suci (Pura) sthana Ida Sanghyang Wdhi dan Ida Bhatara-Bhatari dengan segala rasa bhakti yang tulus, ikhlas dan tanpa pamrih. Caranya, antara lain dengan memberikan dana punia.

(c). Melakukan kegiatan yang bermanfaat bagi kesucian, dan keajegan fungsi Pura,. Caranya, secara rutin melakukan kegiatan bersih lingkungan (ngerisak/mereresik) untuk menjaga kebersihan dan kesucian Pura; mengadakan kegiatan pembinaan umat antara lain melalui dharma tula (diskusi), dharma gita (gegitan), dharma wacana (penyuluhan/pencerahan), termasuk membantu memenuhi keperluan alat peralatan atau perangkat yang dibutuhkan Pura, seperti wadah tirtha, tedung, wastra, dupa, carat colong, arak berem (tetabuhan), dll.

(d) Membantu dengan simpati dan empati memenuhi kebutuhan para perangkat di Pura (prajuru, juru sapuh, juru canang, Pamangku yang selama ini kurang begitu mendapat perhatian. Caranya dengan memberikan punia kepada prajuru Pura, atau membantu pengadaan bhusana Pamangku beserta kelengkapannya, dll.

\section{2) Dalam ranah "Tresna", realisasinya dapat ditampilkan dengan :}

(a) Menguatkan ajaran Tat Twam Asi dalam diri anggota seke sebagai satusatunya cara untuk menjalin hubungan kemanusiaan (intern dan antar) agar lebih mudah dan cepat tercipta suasana kehidupan yang didasari atas azas kesamaan (dalam bingkai perbedaan), rasa kekeluargaan, penuh kerukunan dan selalu mengedepankan cinta perdamaian. 
(b). Menumbuhkembangkan sifat, watak dan atau karakter kemanusiaan yang arif bijaksana atas dasar tuntunan nilai-nilai luhur peradaban leluhur, kebudayaan adiluhur dan rasa keagamaan yang adiluhung. Caranya dengan menjalin kehidupan dalam kebersamaan (pasuka-dukan), hidup berdampingan dengan semangat saling asah-asih dan asuh, serta tidak bersikap saling memusuhi dan juga gemar hidup rukun.

(c) Mempraktikkan secara nyata dalam realita kehidupan sosial, bentuk-bentuk perbuatan yang merefleksikan semangat kepedulian terhadap sesama, misalnya dengan selalu memandang dan menghargai serta menghormati siapapun juga, meski dengan segala perbedaan, kekurangan dan kelemahannya atas dasar filosofi hidup menyama braya (kebersamaan, kekeluargaan) dan druwenang sareng (saling memiliki). Caranya, dengan menguatkan rasa persaudaraan, tidak membesar-besarkan persoalan yang bisa diselesaikan dengan perdamaian dan tidak menggunakan kekerasan dalam memperjuangkan atau memenangkan kepentingan (pribadi, kelompok atau golongan), tetapi lebih mengedepankan piranti musyawarah untuk mencapai kata mufakat

\section{3) Dalam ranah "Eling", realisasinya dapat ditunjukkan dengan :}

(a) Menempatkan dan memandang segala makhluk adalah "sama" sebagai makhluk ciptaan-Nya yang dalam proses berkehidupan sama-sama memiliki "hak" untuk melangsungkan perikehidupannya. Contoh : bersikap saling "menghidupi" lewat cara-cara pemeliharaan, perawatan demi keajegan isi alam (sarwa prani hitangkara)

(b) Menunjukkan kesadaran bahwa keberadaan setiap makhluk apapun bentuk, jenis dan golongannya sebagai bagian dari organisme kehidupan, dimana satu sama lain makhluk berada dalam jalinan keterikatan dan saling ketergantungan. Sehingga, terutama bagi insan manusia yang lebih beruntung diciptakan sebagai makhluk mulia dan sempurna dibanding makhluk lainnya, diharapkan peran dan tanggungjawabnya untuk menjadi pemimpin dan penuntun bagi segenap makhluk menuju kehidupan yang selalu dapat hidup secara serasi, selaras, seimbang dalam keharmonisan. 
(c) Melaksanakan gerakan terkait dengan usaha nyata menjaga keharmonisan dan kelestaran alam beserta isinya. Caranya, dengan melakukan aksi penanaman pohon atau tumbuhan baik yang berkorelasi dengan pelestarian hutan (di bukit gunung atau dataran), atau yang berfungsi keagamaan, seperti menanam/memelihara pohon berbuah atau tumbuhan berbunga yang diperlukan dalam setiap kegiatan ritual yajna. Termasuk mengembangkan usaha peternakan atau penangkaran terhadap jenis-jenis hewan, entah itu untuk memenuhi kebutuhan ekonomi sehari-hari atau untuk usaha pelestarian, termasuk terhadap hewan langka yang acapkali diperlukan dalam kegiatan upacara yajna tertentu (Widana, 2015: 206).

Aspek Eling ini pada akhirnya akan menjadi kata kunci dalam merealisasi bentuk lain dari ritual-yajna yang bahkan diyakini memiliki nilai tinggi, karena telah melingkupi totalitas rasa cinta, tidak saja kehadapan Ida Sanghyang Widhi melalui "Bhakti", tetapi bermanifestasi juga ke dalam bentuk "Tresna" (cinta kasih) kepada sesama dan rasa "Eling" terhadap lingkungan alam beserta segala isinya.

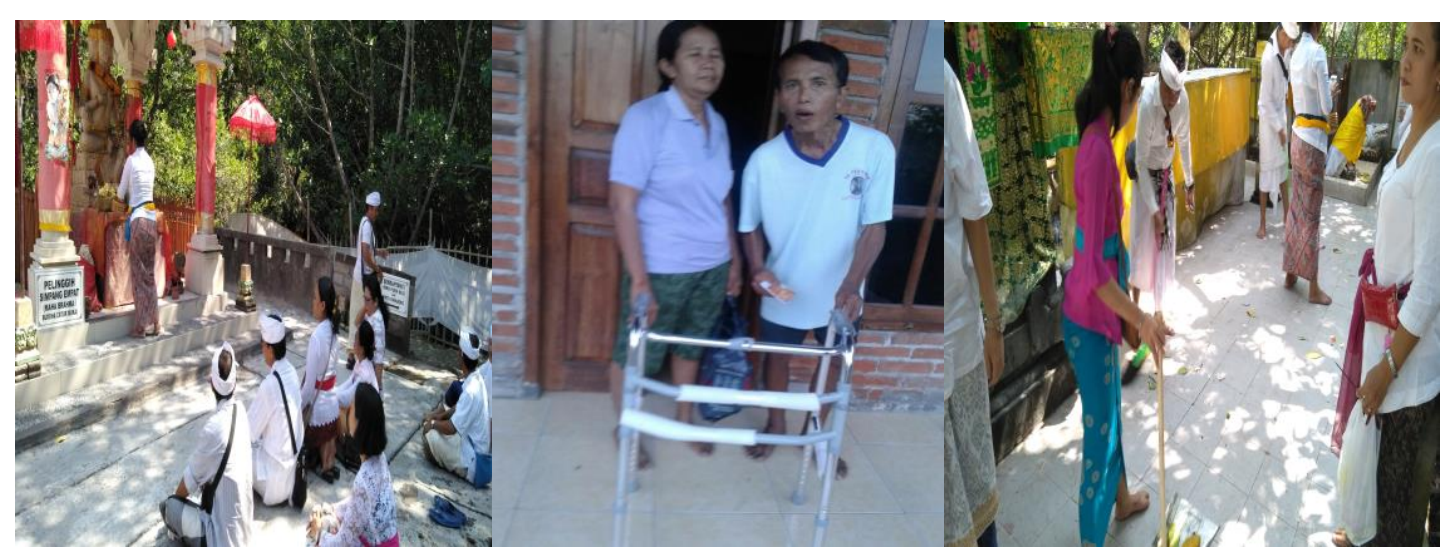

Gambar 3.1. Implementasi "Bhatre" : bhakti (a), tresna (b) dan eling (c)

\subsection{Monitoring dan Evaluasi}

Pelaksanaan monitoring dan evaluasi dilakukan secara berkala setelah selesai tahapan pendampingan dalam kaitan implementasi kegiatan Tirthayatra berbasis bhakti-tresna-eling. Dari hasil monitoring dan evaluasi inilah ditemukan kendala atau kekurangan, terutama yang berkaitan dengan diversifikasi kegiatan Tirthayatra yang sebelumnya hanya melakukan 
acara persembahan dan persembahyangan saja, tetapi kini sudah menambah kegiatan berupa arisan dan menabung.

Penghargaan atau apresiasi juga telah diberikankan oleh tim pelaksana pengabdian terhadap anggota Seke Bhatre yang telah dengan konsisten melaksanakan kegiatan Tirthayatra berupa pemberian buku-buku keagamaan Hindu yang diharapkan dapat meningkatkan pengetahuan dan pemahaman ajaran Hindu bagi para nggotanya.

Monitoring dan evaluasi secara internal yang dilakukan oleh tim pelaksana kegiatan pengabdian terhadap pentingnya dilakukan diversifikasi kegiatan selain persembahan dan persembahyangan, yaitu mendorong anggota Seke Bhatre untuk memvariasikan jenis kegiatannya. Setelah dilakukan pendampingan, monirong dan evaluasi, Seke Bhatre ini akhirnya menambah kegiatan lainnya yang masih berada dalam satu kesempatan Tirthayatra, yaitu : (1) mengadakan arisan senilai @ Rp. 50.000,-; (2) menabung, terutama bagi anggota yang mendapat/menarik arisan didorong untuk sebagian disimpan sebagai tabungan, yang suatu saat bisa diambil dan digunakan untuk biaya Tirthayatra keluar Bali yang tentunya memerlukan dana relatif lebih besar untuk keperluan transportasi; (3) memotivasi anggota seke agar berkenan membantu anggota lainnya yang sedang dalam keadaan sakit, melalui pungutan dana suka-duka yang besarannya sesuai kemampuan dan keikhlasan. Contohnya memberikan bantuan dana dan tongkat pegangan untuk teman sejawat yang sedang dalam keadaan sakit stroke di daerah Buleleng; dan (4) melakukan kegiatan bersih-bersih (ngerisak) di area dalam dan luar tempat suci/Pura. Sesekali juga memberikan bantuan pepohonan untuk ditanam di sekitar area tempat suci, terutama pohon yang berhubungan dengan kebutuhan sarana persembahyangan, seperti pohon jepun, kelapa, plawa, dll.

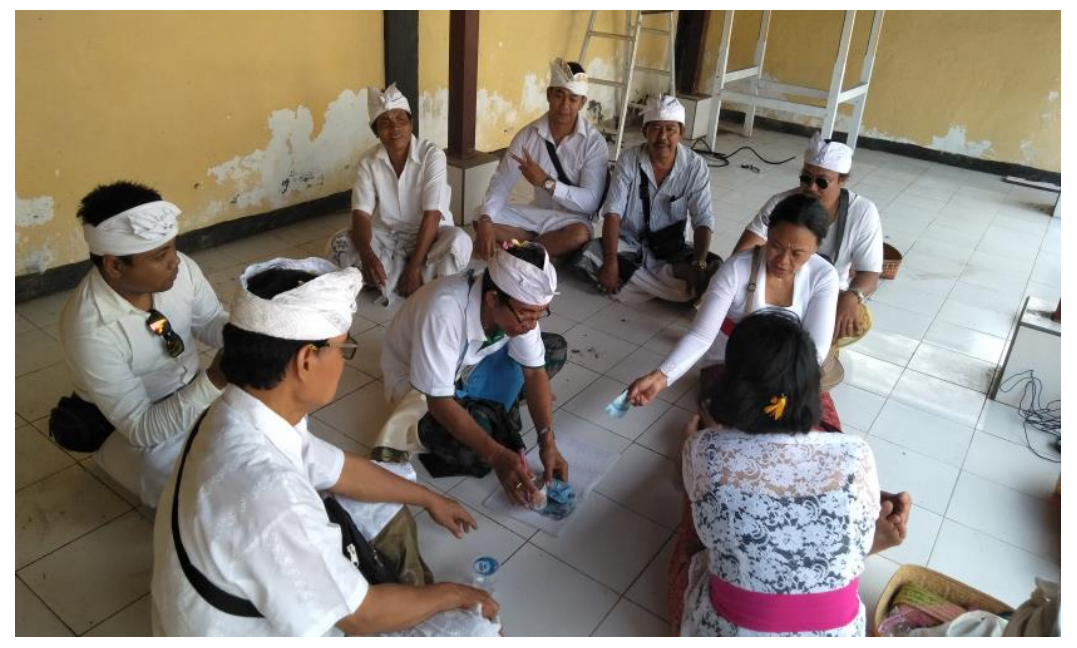

Gambar 3.2. Penambahan kegiatan Arisan dan Tabungan 


\section{Simpulan Dan Saran}

\subsection{Simpulan}

Simpulan dari kegiatan pengabdian kepada masyarakat terhadap kelompok Seke Bhatre di Br. Lumbung Sari, Desa Pakraman Denpasar ini adalah : 1) terjadi pemahaman yang lebih mendalam terhadap arti dan makna ajaran Tri Hita Karana dalam format konsep "Bhatre" yang kemudian diimplementasikan melalui kegiatan Tirthayatra; 2) terjadi penguatan dan peningkatan sradha dan bhakti anggota Seke Bhatre, yang sebelumnya hanya sekedar melaksanakan kegiatan Tirthayatra dengan anggapan sebagai kegiatan rekreasi; 3) tumbuhnya kesadaran akan pentingnya arti pemujaan kepada Tuhan diperluas maknanya dalam kemasan "Bhatre", yaitu memantapkan rasa "Bhakti" (vertikal-niskala) kehadapan Ida Sanghyang Widhi (Tuhan Yang Maha Esa), memupuk rasa "Tresna" (horizontal) dengan saling mengasihi antar sesama manusia, dan menumbuhkembangkan sikap "Eling" (vertikalsakala), terutama terhadap lingkungan alam agar keadaannya tetap harmonis dan lestari. Hanya dengan begitu, praktik keagamaan umat Hindu akan mempunyai korelasi positif dan konstruktif terhadap usaha penguatan dan peningkatan sradha dan bhakti umat, dalam rangka mencapai tujuan hidup sejahtera dan bahagia lahir-bathin, duniawi-rohani : moksartham jagadhita ya ca iti dharmah.

\subsection{Saran}

Mengingat makna dan manfaat Tirthayatra berbasis Bhakti-Tresna-Eling itu sangat bernilai bagi usaha menguatkan dan meningkatkan sradha bhakti umat, maka disarankan agar kegiatan Seke Bhatre di Br. Lumbung Sari, Desa Pakraman Denpasar dalam kemasan mengunjungi (pedek tangkil) ke tempat-tempat suci/Pura/Kahyangan ini terus dilanjutkan.

\section{Ucapan Terimakasih}

Ucapan terimakasih yang sebesar-besarnya dan penghargaan setinggi-tingginya kepada kelompok Seke Bhatre, baik dari unsur pimpinan pengurus maupun seluruh anggota beserta keluarganya yang telah memberikan ruang dan waktu tim pengabdian kepada masyarakat ini untuk melakukan pendampingan guna menguatkan sekaligus meningkatkan sradha (iman) dan bhakti (taqwa) umat Hindu, khususnya anggota Seke Bhatre. Semoga apa yang telah dilakukan tim dapat bermanfaat sehingga tujuan mulia Seke Bhatre untuk mencapai moksartham jagadhita ya ca iti dharmah, astungkara bisa tercapai. 


\section{Daftar Pustaka}

Antara, Nala I Gde (Ed). 2009. Kamus Bali-Indonesia Beraksara Latin Dan Bali. Denpasar : Badan Pembina Bahasa, Aksara, dan Sastra Bali.

Pudja, G. 1981. Sarasamuscaya. Jakarta: Mayasari

Titib, I Made. 1993. Pedoman Sembahyang dan Tirthayatra Bagi Umat Hindu. Denpasar: Upada Sastra

Widana, I Gusti Ketut. 2015. Banten Siap Saji, Pentas Konsumerisme Di Panggung Ritual. Denpasar : Pustaka Bali Post.

Wirawan, I Made Adi. 2018.Tri Hita Karana Kajian Teologi, Sosiologi, dan Ekologi Menurut Veda. Surabaya : Paramita 